\title{
Forest Fires: \\ Evaluation of Government Intervention Measures
}

\author{
Xavier Ballart \\ Universidad Autónoma de Barcelona \\ xavier.ballart@uab.es \\ and \\ Clara Riba \\ Universidad Pompeu Fabra \\ clara.riba@econ.upf.es
}

March 2000 


\title{
Key words:
}

Forest fires, policy evaluation

\begin{abstract}
The purpose of this paper is to examine the relation between government measures, volunteer participation, climate variables and forest fires. A number of studies have related forest fires to causes of ignition, to fire history in one area, to the type of vegetation and weather characteristics or to community institutions, but there is little research on the relation between fire production and government prevention and extinction measures from a policy evaluation perspective.
\end{abstract}

An observational approach is first applied to select forest fires in the north east of Spain. Taking a selection of fires with a certain size, a multiple regression analysis is conducted to find significant relations between policy instruments under the control of the government and the number of hectares burn in each case, controlling at the same time the effect of weather conditions and other context variables. The paper brings evidence on the effects of simultaneity and the relevance of recurring to army soldiers in specific days with extraordinary high simultaneity. The analysis also brings light on the effectiveness of two preventive policies and of helicopters for extinction tasks. 


\section{Introduction}

In the last 20 years, there have been dramatic forest fires in the north east of Spain. Forest fires have been particularly intense in 1986 and in 1994 while they were important but less damaging in 1980, 1981, 1983 and 1998 -. Like in other regions along the Mediterranean shore - as in the south of France or in Greece, forest fires take place every now an then, reaching some years proportions of a human and natural catastrophe. In almost every continent of the world, similar problems happen with regularity like in California and Chile, New South Wales in Australia or South Africa.

Systems of prevention and extinction work rather well with a majority of fires but seem to fail completely with very few bigger fires that have the worse consequences in terms of human life, destruction of forest vegetation and wildlife, and loss of economic opportunities. Those few big uncontrolled forest fires also have the worst effect on people's trust generating a sense frustration in the population that literally observe how their country burns to ashes. This is a policy area where government could be said to be "playing with fire", since success can turn into a radical failure from day to night. Regional and local governments have taken a number of actions to prevent fires and to avoid the extension of fires once ignition has taken place. But the summers of 1994, and to a lesser extent 1998, have put into question the whole policy given the size of the areas burnt and the feeling of disaster among the population.

As in the case of other policies where public administrations deal with a risk, effectiveness can not be judged on the basis of one single parameter. There are many factors that lead to the 
non-desired result and it would not be correct to only judge on the basis of people dead, hectares burnt or total value of economic damage. At the same time, it is true that some strategies and some actions may be more effective than others in given contexts and therefore, it is urgent to bring light to those. The ultimate measure of effectiveness with regard to forest fires would be the lives saved, the forest that did not burn or the damage that was not produced because of the action taken to prevent, control and extinguish forest fires. But the hypothetical question of what would have happened if measures had not been taken is not simple to address.

Measures taken by the regional government - with the co-operation of local governments can be considered the policy. Given the multicausal nature of the problem, the policy attempts to encompass different aspects that may contribute either to prevent fires before they happen or to control and extinguish them after they have taken place. The policy is based on a two fold theory: first, it is based on the assumption that it is possible to determine where and when forest fires may take place and to distribute resources rationally, optimizing the surveillance and the extinction. And second, it is based on the assumption that community mobilization through volunteer firefighters and volunteer associations that do prevention tasks in the rural areas can help to detect fires and keep them under control. Volunteers with share or mutual interests (whether it be their property, the preservation of the forest as a common good or having a better equipped fire protection service) can contribute helping in almost any kind of need, while mobilizing the community in defense of the nature and the population living in the countryside. 
The purpose of this paper is to examine the relation between government measures, volunteer participation, climate variables and forest fires. A number of studies have related forest fires to causes of ignition (Davis, 1959; Rothermel, 1972; Pyne, 1984; Burgan and Rothermel, 1986; Andrews, 1986), to fire history in one area (Johson and Van Wagner, 1985; Dansereau and Bergeron, 1993) and to the type of vegetation and weather characteristics (ICONA, 1982; Palmieri and Cozzi, 1983; Martell and Bevilacqua, 1989). Other studies have attempted to model the behavior of fire in specific spaces and times (Rothermel, 1972; Deeming et al.,1978; Pyne, 1984). Finally, a few studies relate volunteer participation and community institutions with fire control (Lozier, 1976; Kurien and Bakhshish, 1996).

However, there is not much research on the relation between fire production and government prevention and extinction measures from a policy evaluation perspective. Thus, we were interested in examining whether there was a difference in the effects depending on government measures, context, professional and volunteer participation of some kind.

An observational approach is first applied to select forest fires in the region. Taking a selection of fires with a certain size, a multiple regression analysis is conducted to find significant relations between policy instruments under the control of the government and the number of hectares burn in each case, controlling at the same time the effect of weather conditions and other context variables. The statistical approach to evaluating public policies is viewed as an adequate methodology to analyze the problem of forest fires on the basis that number of hectares burnt is a good representation on the non-desired result for the purposes of the analysis. 


\section{Problem definition}

a.) Forest continuity

There is a ample evidence on the fact that in the last 70 years, the extension of forest mass in Catalonia has significantly grown due to the decrease of population in rural areas and to the migration of the people living in the countryside to the cities and metropolitan areas. The reduction in agricultural uses did not often translate into the commercial exploitation of the forest, since the economic incentives for doing so were not in place. The result of natural reforestation has been the accumulation of ignitable material in a major part of the country, the arboreal mass occupying $61 \%$ of the territory.

Some policy alternatives center around the idea of dividing the forest into plots. The idea of cutting the fire with artificial divisions of the forest is seen as an adequate measure to stop fires and facilitate access to firefighters. But the measure is also seen as ineffective and politically risky, given the difficulty to maintain the divisions clean of vegetation and the reluctance to accept that in order to save nature, administrations need to cut trees and open spaces in the forest.

Other policy alternatives are based on the idea to bring back people to farming and to the traditional activities associated to agriculture and forest management. Farmers traditionally cleaned the forest, cut wood for heating and burned bushes when necessary. Others argue that similar results could be pursued by present forest owners if their activity was financially sound. The claim for aid from the administration is justified, according to forest owners, on the ecological and social benefits the society obtains from forests. 


\section{b.) Urbanization}

The region of Catalonia is highly populated with over 6 million people concentrating on a third of the territory that extends along the Mediterranean coast. With an income level that is slightly above the average of the European Union, many urban residents living in the metropolitan area of Barcelona have bought second residences in the countryside where they go on weekends and for holidays. The frequent visitation of the forests by urban residents together with the sudden increase of tourists during the summer months pose a serious threat to the forest, increasing the chances of uncontrolled fires. The climate is typically Mediterranean with four clearly marked seasons. Summers may have long dry periods with temperatures reaching the thirties - Celsius - in July and August and the wind may blow occasionally with considerable strength.

Various policy alternatives focus on the contact points between nature and human activities: the regulation of residential areas, cycling and hiking paths, town landfills, highways, railways, electricity lines..., is expected to reduce the number of fires starting at those points. Regulation can suggest or induce a desired behavior or it can impose serious constraints to human activity in order to achieve policy objectives. Some of the measures may even prohibit certain activities at times or places where there is a high risk of ignition. However, regulations are not effective unless there is a threat and certainty of a punishment for a prescribed behavior and the surveillance and sanctions are maintained over time. Implementation difficulties or the easing of the tension in the mid-term can easily make public measures ineffective. 
c.) Lack of coordination

During the forest fires of July and August 1994, and to a lesser extent in 1998, professional firefighters experienced serious problems of coordination, both internal and external. Internal coordination problems arose on specific days where there could be up to 28 uncontrolled fires at the same time. Urgency to act on various places at the same time made decision-making very difficult at the headquarters. Certain areas had to wait to receive help from better equipped professional firefighters because they were busy attacking fires somewhere else. External coordination problems also appeared when local governments and local volunteers were the first to fight fires replacing professional firefighters. Professional firefighters understood that volunteers were sometimes putting themselves in jeopardy or being more of an obstacle than a help. Mayors, however, act on the basis of their political authority and volunteers have a direct interest in the preservation of their environment and, often, a better knowledge of the territory.

More resources, whether it be more human resources - professional firefighters, forest specialists firefighters - or more material resources - engine fires, helicopters, planes or systems of communication - is viewed as part of the solution to the problem of simultaneity. Norms and plans for action al the local level in emergency situations is the alternative the government has adopted with the co-operation of local governments in order to prevent coordination problems between different parties at the moment of fighting fires. Here again, both measures can be viewed critically, since on one side, resources are scarce and an equilibrium needs to be reached between risk an public expenditure, and, on the other side, plans are designed to be implemented, but critical situations and cumulated tension may turn the best plan worthless. 
d.) Non natural succession of species

Another definition of the problem is concerned with the natural process of substitution of species in the forest. The region of Catalonia traditionally has had pine groves, oak groves and cork groves. There are also beech groves with taller trees and less underforest in more humid and mountainous areas. Those are more difficult to burn. According to natural biologists, the vegetation forming the underforest is at present more pyrophite than it used to be, burning more quickly and spreading faster the fire. There is a substitution of species which is not a problem in itself - but can progressively change the ecosystem and have an effect on the spreading of fires. The ecological succession of species would have prevented this situation that has been helped by both, human intervention and forest fires.

Any policy measures that would help to restore the woods as they would naturally be can help to preserve the natural succession of species. Reforestation of pine groves, oak groves and cork groves is one alternative that has been debated. Other measures are directed to control the risk of erosion by regulating the felling of trees after a fire to sell the wood that is half burnt. The sad aspect of a burned area and the opportunity to make some money out of a disaster work against policy options imposing limitations on the property rights of owners in a critical situation.

\section{Policy alternatives}

a.) Formal authority and coordination 
In Spain, there was a Law of Forest Fires from 1968 and an agency - ICONA- in charge of prevention and extinction of forest fires depending on the central administration. In a general process of decentralization, the central government transferred the management of forest fires to the region of Catalonia in the early eighties, for its territory. The central agency of civil protection issued in 1993 a basic instruction on forest fires ${ }^{1}$ which was developed by the regional government in the so called INFOCAT, an emergency plan for local authorities. The Catalan INFOCAT was prepared during 1993 and approved in September 1994, after one of the worst summers in history in terms of forest fires. The INFOCAT regulates the tasks of various actors may have during emergencies and gives the commanding capacity to the professional firefighters.

b.) Fire prevention and extinction services

In 1986, the other worst summer in the recent history of forest fires, the regional government started the so called Foc Verd ${ }^{2}$ program, which put the bases to build the system of prevention. Since the early nineties, the system of prevention is based on three pillars:

- the daily map of risk which is prepared through remote sensing and geographical information systems applied to forest fire management;

- the surveillance units in the forest - rural agents with police functions, surveillance towers, transmission personnel and intervention groups - and in the air - a plane and an helicopter; - and the volunteers forming the ADF - forest defense associations - which were created within the context of the Foc Verd program on the basis of existing groups and associations that traditionally had organized themselves to defend their property and environment.

\footnotetext{
${ }^{1}$ Boletín Oficial del Estado, number 90, 15th April 1993.

${ }^{2}$ Literally "Green Fire".
} 
The system of extinction was less subject to innovation in its policy and operations. It is a traditional structure of fire fighters that have seen how resources experienced an slow incremental growth through the years. In 1994, the extinction program counted with 1,327 professional firefighters ${ }^{3}$ distributed in 70 parks and, 1,700 volunteer firefighters distributed in 80 other parks, 725 vehicles of various kinds, 3 permanent helicopters and a variable number of planes and helicopters of various kinds that were used but did not necessarily belong to the government.

The fire prevention service did open spaces and facilitate access to forests when it was estimated necessary. However, it did not enter into an aggressive policy of artificial division of the woods or fighting fire with controlled fire during the winter season.

\section{c.) Regulation and incentives}

The Catalan government has been regulating multiple activities and imposing obligations with a prevention objective. Some examples are the regulation of the distance where landfills can be authorized, the obligation to clean the corridors under electricity towers, the establishment of a minimum perimeter for residential areas in the forest and the obligatory cleaning of road and railway sides.

Other times, the government offered some economic aid as an incentive to induce activities that were perceived as directly related to prevent fires or repairing their consequences. That was the case with the creation of a special fund for artificial regeneration or the help that was

\footnotetext{
${ }^{3}$ Excluding the city of Barcelona which is the only municipal government with its own Fire Department.
} 
offered to farmers to buy a type of goat with a powerful capacity to clear weeds. Table 1 summarizes policy alternatives and policy measures that were adopted by the Catalan government since the mid eighties. The table differentiates according to the type of policy.

\section{Table 1 Policy alternatives and policy measures}

\begin{tabular}{|c|c|}
\hline Policy alternatives & Policy measures \\
\hline Direct provision & Direct provision \\
\hline 1. Artificial division of forests into smaller woods & Not implemented \\
\hline 2. Investment in human resources & $\begin{array}{l}\text { 2. Increase in the number of professional } \\
\text { firefighters and rural agents }\end{array}$ \\
\hline \multirow[t]{2}{*}{ 3. Investment in equipment and vehicles } & $\begin{array}{l}\text { 3. Investment in equipment and vehicles, } \\
\text { including control towers and water points }\end{array}$ \\
\hline & 4. Investment in technology to analyze daily risk \\
\hline Public regulation & Public regulation \\
\hline 1. Regulation of activities that may start fires. & $\begin{array}{l}\text { 1. Regulation of landfills, electricity towers, } \\
\text { perimeter of residential areas, road and railways } \\
\text { side cleaning. }\end{array}$ \\
\hline 2. Regulation of activities that may cause erosion & Not implemented \\
\hline 3. Coordination & 3. Emergency plans to achieve better coordination \\
\hline Economic incentives & Economic incentives \\
\hline $\begin{array}{l}\text { 1. Facilitate the return of the population to the } \\
\text { countryside and to rural life }\end{array}$ & Not implemented \\
\hline $\begin{array}{l}\text { 2. Facilitate the natural process of succession of } \\
\text { species. }\end{array}$ & Not implemented \\
\hline 3. Facilitate the artificial regeneration of the forest & 3. Aid to forest owners \\
\hline 4. Financial aid to volunteer associations & 4. Aid to forest defense associations (ADFs). \\
\hline Source: Table by X. Ballart and C. Riba & \\
\hline
\end{tabular}




\section{Research design and data sources}

Given the multicausal nature of forest fires, it is rather difficult to evaluate government actions to prevent and extinguish fires. First, there is the question of the weather and natural conditions of the territory and second, there is not a single intervention. Public intervention is actually a combination of actions that may have a marginal effect in the production of a fire. Some of the actions are more the result of political pressure to do something than the consequence of careful and exhaustive analysis. Other actions make sense to any professional in the sector but may have a small contribution towards the desired effects. For example, having control towers may be useful to detect fires but the fact that a fire is detected by a forest agent may not have any effect on the extension of the fire.

In the case of forest fires, the objectives are clear but the means to achieve those objectives are rather uncertain. In other words, we do not have the technique to control or prevent forest fires. The question is what government actions - and under what conditions - are effective in reducing the damage to nature, to humans or to private property. We would like to be able to tell the government what is doing right or wrong and what specific policies translate into a significant decrease in the extension of a fire. However, as important as government actions are climate, topography and other contextual factors. Finding what incidence they have in the problem might facilitate the adoption of more effective prevention and extinction measures.

Multiple regression analysis was used to determine the impact of different types of variables in the extension of forest fires. The available data for the period under study permits the construction of a model where human intervention - prevention and extinction - and some 
weather and contextual characteristics are included. The variables under study cover rather well the extinction policy - personnel and vehicles, response and control times - but it does not include any information that may be related to the actions taken to prohibit certain activities or financially help forest owners - public regulation and economic incentives measures in table 1-. The analysis followed a strategy that consisted on estimating the dependent variable on the basis of three different groups of factors. A model was estimated for each group of variables in order to include all significant variables in a final model.

In order to measure the significance of each forest fire, three alternatives were considered. One possible dependent variable was economic loss, measured as a sum of all kinds of damage produced by the fire. However, data was incomplete regarding economic loss that is no strictly related to direct damage on housing or lumber and agricultural businesses. A second alternative is the number of people that died or were injured during a fire. This possibility did no seem adequate since this is an event that, fortunately, does not happen very often. The alternative that was considered to measure the significance of the fire is the number of hectares burn in each case - cases being defined by the regional administration in their data bases. The problem with hectares burnt is that the consequences of two fires with the same extension can be very different since the area that is burnt can be trees, brushwood or farm fields. At the same time, however, and considering the data available, this measure is considered a good representation of the significance of fire in each case.

Explanatory variables were grouped in three different categories: 
- The first group includes climate related variables (humidity, max temperature and wind speed) together with some others concerning topography (location with relation to the sun or the shadow), orography (flat, hilly or rocky) and other characteristics of the place where the fire started (near a house, path or road or in the middle of the forest, whether it is a forest with trees burning or any other kind of vegetation, and simultaneity with other incidents during the same day).

- The second group includes two prevention related variables: the first is a specific information on whether the fire was detected by a permanent guardian watching for fires, and the second is the daily evaluation of the risk as it is done by personnel in charge within the prevention services.

- The third group of variables measure extinction factors including human resources and material resources that take part in the extinction. Human resources can be professional fire fighters, volunteers, army personnel, police forces, forest rangers and other public services related personnel. Material resources include fire engines, tractors, helicopters, fire prevention planes, fire attack planes and sea planes.

The analysis is based on data from the Direcció General del Medi Natural of the regional government of Catalonia. This unit collects detailed information on all fires that take place in the region. For this research, we used data on all forest fires that took place in the period 1992-1995 reaching a total of 3.132 cases. The selection of years is based on the fact that the biggest crisis happened in 1994. As it was said, 1998 was also a bad year but it was basically due to one big fire. Data was restructured and transformed for the purposes of the analysis. 
The fact that the majority of fires are rather small, with an extension of less than one hectare, while a few fires may account for thousands of hectares, introduces a strong asymmetry in the distribution of the dependent variable, with a long tail on the right (see table 2). For this reason cases where the extension burnt was smaller than a one hundred part of an Ha. were excluded (15\% of the cases). In the cases remaining, the dependent variable that is used is the decimal logarithm of the number of hectares burnt in each fire, which has a more symmetric distribution than the original variable ${ }^{4}$. With this procedure, the total number of cases is 2,653 .

Table 2. Size of forest fires (1992-1995)

\begin{tabular}{lcc}
\hline & Percentage & Cumulative percentage \\
Burnt area < 1 Ha. & 68.8 & 68.8 \\
$1 \mathrm{Ha} . \leq$ Burnt area < 3 Ha. & 16.3 & 85.1 \\
$3 \mathrm{Ha} . \leq$ Burnt area < 50 Ha. & 12.0 & 97.1 \\
$50 \mathrm{Ha} . \leq$ Burnt area < 6,000 Ha. & 2.8 & 99.9 \\
Burnt area < 13,000 Ha. & .1 & 100.0 \\
\hline
\end{tabular}

Source: Data from DGMN, Generalitat de Catalunya. Table by X. Ballart and C. Riba.

\section{Analysis and results}

A correlational analysis was first performed to see whether the explanatory variables are associated to fire extension. This first analysis also informs about the sign of the association and whether it corresponds to what was expected.

\footnotetext{
${ }^{4}$ This is a quite common strategy for facilitate an easy treatment of variables that are severely skewed. For an explanation about the convenience to transform the observed data points by means of some mathematical
} 
Climate, topography and other contextual factors

Maximum temperature and wind speed present a positive and significant correlation with the dependent variable. It was also found a significant correlation with humidity, but in this case the sign, as expected, was negative.

Topography variables also have a significant and positive correlation with the dependent variable. That is, the more abrupt the land is and the more it is oriented towards the sun, the more it burns.

Other contextual factors were considered. The number of simultaneous fires in a day shows a clear and positive relation with the hectares burnt. Whether the fire was detected in the middle of the mountains, near some kind of dwelling o near a path or road is related to the size of the fire but in this case the correlation is not very significant. The distinction between forests and other types of land that may burn (fields, brushwood) does not seem to have any relation with the size of the fire.

A regression model was run including all variables from that group of factors that were significant (all but the variable indicating whether the place that burnt was a forest). The resulting model is significant and explains a $14,4 \%$ of the total variation of the size of fires (see Table 3, Model 1). All the variables introduced are significant except for the one indicating the place where the fire was first detected (in the mountains). Signs were as 
expected and the variables that seem to have a bigger impact are wind speed and slope of the land, as it can be deduced from the values of the standardized regression coefficients.

\section{Prevention related factors}

Two prevention variables, one indicating whether the fire was first detected by a person in charge of permanently watching for the ignition of fires in nature and a second one that corresponds with the evaluation of risk as it is performed daily by central prevention services, show significant correlations with the size of burnt land.

Including these two variables in the previous model, maximum temperature is no longer significant and therefore it is excluded from the model. All the other variables continue to be significant and maintain the same signs and very similar coefficient. The model explains a $15.4 \%$ of total variation.

The way these preventive measures may work is reducing the response times of personnel and vehicles by land or air. The analysis shows that with regard to forest guards, there is a statistically significant difference between the instances where fires were/were not detected by guards. ${ }^{5}$ The risk analysis of ignition in a particular day has a strong significant and negative

\footnotetext{
${ }^{5}$ For the purposes of a T-test analysis, cases were classified in three categories with the following results:

- In forest fires of less than $3 \mathrm{Ha}$, the average response time aerial and terrestrial is reduced a $28 \%$ in those instances where the fire is detected by a guard.

- In fires of a size between 3 and $50 \mathrm{Ha}$, terrestrial response time is reduced in a $60 \%$ and aerial response time is reduced a $62 \%$;

- In bigger fires, there are not significant differences in the response times due to the enormous dispersion in the response time and the relatively low number of cases. Simultaneity might play a role since vehicles can not reach all the places at the same time.
} 
correlation with terrestrial response times. There is no significant correlation of such measure with aerial response times. ${ }^{6}$

\section{Extinction related factors: human resources}

Another group of variables indicates the number of different categories of people contributing to the extinction of a particular forest fire (firefighters, civil personnel, army soldiers, municipal government workers, police forces and forest technical people). All the variables have significant and positive correlations with the dependent variable. However, since most of them have a curvilinear relation with fire size, they were transformed through the calculation of the square root of their values with the purpose to make more linear the relation and avoid functional specification problems ${ }^{7}$.

In a model where only people related variables are included, two extraordinarily severe residuals were found. They were corresponding to two cases where 390 and 3.785 Ha were burnt. They happened the $4^{\text {th }}$ of July of 1994 and the $10^{\text {th }}$ of August of 1994, the two worst days in the recent history of forest fires in the region with 28 and 23 simultaneous fires.

Looking for a distinctive characteristic of those two fires, it was found that no-one went to extinguish them, something which also happened in just one other case, the $6^{\text {th }}$ of April of 1994. That fire was smaller (20 Ha) because it happened during a day of spring (while the

6 The correlational analysis shows in this case that:

- In forest fires of less than $3 \mathrm{Ha}$, there is a significant, negative, not very strong relation of applying such strategy and terrestrial response time: $r=-0.073$ (sign. $=0.000$ );

- In fires of a size between 3 and $50 \mathrm{Ha}$, the relation between the two variables is stronger: $r=-0.231$ (sign. $=0.000)$;

- In bigger fires, the correlation between probability of ignition and terrestrial response times is also negative, significant and stronger than in the two previous cases: $r=-0.264(\operatorname{sign} .=0.015)$. 
other two were in summer), but there was also a considerable number of simultaneous fires (11). The residual in this case, even being not as severe that of the two other cases, is also important. In all other instances where firefighters were not present at a fire, they were substituted by another type of personnel, usually civil personnel, police forces or some kind of municipal workers.

Excluding those three exceptional cases, the model including all the significant variables was estimated. All the variables are significant, except for the number of police officers that was subsequently excluded, the signs of the coefficients are as expected and the residuals do not present any important problem (see Table 3, Model 2). At this stage of the analysis, the bigger size of fires seemed to be related to the following factors:

- the speed of the wind and the low humidity of the air,

- the simultaneity of fires, the abrupt nature and the orientation towards the sun of the terrain,

- the non detection by permanent guardians, and the estimation of a low probability of fire when it did happen after,

- the increasing number of different categories of personnel sent to extinguish the fire.

The fact that human resources variables have a positive sign can be explained by the presence of causality in an inverse sense. As fires become bigger and bigger, more people are sent to control and extinguish them. The only exception to that pattern is the army personnel, which has a negative sign. This finding might be related to the fact that army soldiers are rarely used or that they are only used when fires take very big proportions and start to be seen as a serious

\footnotetext{
${ }^{7}$ For a detailed description about the assumptions of the linear regression model and the use of graphical displays to detect violations and to choose the best transformations to avoid it see Hamilton (1992).
} 
catastrophe. Big fires, where army soldiers participated in extinction tasks, were controlled sooner and burn relatively less than those other big fires that did not have that specific resource.

Thus, preventive measures such as permanent guardians and analyzing the risk of fire seem to be effective, the same way that calling the army is an effective measure to control big fires.

\section{Extinction related factors: material resources}

The last group of variables that is related to the size of forest fires is material resources. There are two kinds of information regarding material resources: on one hand, the use of different types of vehicles in the extinction tasks. On the other hand, the number of times different types of planes and helicopters released their tanks of water from the air on a forest or land that was burning. ${ }^{8}$

Both types of variables, number of vehicles participating in extinction tasks and number of water discharges from the air are strongly and significantly correlated in a positive sense. The regression model that forecasts the extension of the land that burns from the nine variables containing information on material resources is significant and explains $42 \%$ of total variation. All the variables are significant, except for the number of helicopters due to its strong correlation with the number of water discharges from helicopters. As in the case of human resources, there is also an instance of inverse causality since bigger fires attract more vehicles. However the negative sign of the coefficients of the variables that contain

\footnotetext{
${ }^{8}$ Water discharges were also transformed through their squared root with the purpose to make more linear the relation between the dependent variable and to void functional specification problems in the model.
} 
information on the number of water discharges indicates that with the same number of vehicles, more discharges are efficient in having less territory burnt.

\section{Table 3}

\section{Regression models for forest fires}

Dependent variable $=$ Number of burnt Ha. $($ transformed with logarithm $)$ Entries are regression coefficients

\begin{tabular}{|c|c|c|c|c|c|c|}
\hline & Model 1 & & Model 2 & & Model 3 & \\
\hline Humidity & -0.006 & $* *$ & -0.004 & $* *$ & -0.004 & $* *$ \\
\hline Temperature (maximum) & 0.006 & $*$ & & & & \\
\hline Speed of wind & 0.014 & $* *$ & 0.006 & $* *$ & 0.006 & $* *$ \\
\hline Simultaneity of fires & 0.017 & $* *$ & 0.006 & $*$ & 0.005 & $*$ \\
\hline Slope & 0.270 & $* *$ & 0.110 & $* *$ & 0.092 & $* *$ \\
\hline Sunny side & 0.145 & $* *$ & 0.119 & $* *$ & 0.108 & $* *$ \\
\hline Detected by permanent guard & & & -0.070 & $* *$ & -0.068 & $* *$ \\
\hline Risk of fire & & & -0.003 & $* *$ & -0.003 & $* *$ \\
\hline Fire fighters & & & 0.206 & $* *$ & 0.157 & $* *$ \\
\hline Civil Personnel & & & 0.033 & $* *$ & 0.028 & $* *$ \\
\hline Army personnel & & & -0.139 & $* *$ & -0.145 & $* *$ \\
\hline Municipal workers & & & 0.085 & $* *$ & 0.061 & $* *$ \\
\hline Forest technical personnel & & & 0.065 & $* *$ & 0.055 & $* *$ \\
\hline Fire engines & & & & & 0.010 & $* *$ \\
\hline Hidro & & & & & 0.175 & $* *$ \\
\hline Helicopters & & & & & -0.047 & $* *$ \\
\hline Planes & & & & & 0.144 & $* *$ \\
\hline Discharges helicopters & & & & & 0.045 & $* *$ \\
\hline Discharges planes & & & & & -0.072 & $*$ \\
\hline Constant & -1.060 & $* *$ & -1.307 & $* *$ & -1.124 & $* *$ \\
\hline Adjusted $\mathrm{R}^{2}$ & 0.144 & & 0.540 & & 0.563 & \\
\hline
\end{tabular}

** Significant at 0.01 level; * Significant at 0.05 level

Finally, this group of variables was added to the previously estimated model. The result is a model that explains $56 \%$ of the total variation on the basis of weather and location 
characteristics, prevention measures, human and material resources used to control and extinguish the fire (see Table 3, Model 3). The sign and the value of the estimated coefficients for the variables that were included in Model 2 is roughly the same, which can be interpreted as a sign of the robustness of the model. The added variables have a positive sign in the case of number of vehicle and a negative sign in the case of water discharges, except for helicopters that have their signs changed: number of vehicles has a negative coefficient and number of discharges has a positive coefficient. This fact can be interpreted in the sense that other circumstances remaining constant, and even if the number of water discharges is the same, increasing the number of helicopters attacking a fire will reduce its size.

\section{Conclusions}

The first conclusion that may be reached with the analysis is that sending human and material resources to control and extinguish fires is effective. With a certain level of resources, simultaneity as it happened the $4^{\text {th }}$ of July and the $10^{\text {th }}$ of August of 1994 may play a significant role in the uncontrolled expansion of some forest fires. This situation may even happen during times of the year or days when big fires were not expected as in April 1994. A low capacity to respond may result in not sending extinction resources and, consequently, in a bigger expansion of a fire than it would have happened had some kind of resources been sent. In a situation of very high simultaneity, sending army soldiers is a good measure to avoid reaching a point of chaos as it happened during the first weeks of July and August of 1994.

The two preventive measures that could be included in the analysis have proven to be effective. The policy of placing guardians that watch for the ignition of fires has a positive 
effect in reducing the number of Ha. that eventually may burn. This preventive strategy seems to be more effective in reducing response times both by land and air of forest fires of small and medium size. The policy to determine the risk of fire on a specific day and area has a positive effect in the reduction of Ha. when the fire is produced. It may be interpreted that the fire alert activates the system and, as a consequence, extinction tasks are more effective and terrestrial response times reduced.

The material resources that seem more valuable for extinction tasks are helicopters. Increasing the number of helicopters is a rational measure that will translate into significant reductions in the number of Ha finally burnt. Everything else constant, increasing the frequency of the water discharges from the air is also an effective measure to reduce the size of forest fires.

It is interesting to see the variation in the effects of the two main vehicles - helicopters and planes- and their water discharges from the air. The differences in the sign might be related to the characteristics of both types of aircraft. Helicopters seem to be more manageable and better equipped to land in small spaces to refill their tanks with water from any source and to quickly discharge on the fires. Increasing the number of helicopters and attacking the fire simultaneously might result in an effective strategy to control and stop the fire. On the contrary, planes need more ample spaces both in the air and at the time of landing. They are slower to fill tanks, take off and land. Their effectiveness is related to the number of discharges they release more than the number of units working simultaneously. 


\section{Annex}

Since the dependent variable and some of the independent variables were transformed in order to make more linear the relation, it is difficult to interpret the coefficients beyond their sign. The fact that the dependent variable is a logarithm means that the effects are not constant: they are bigger for low values than for high values of the explanatory variable.

In order to calculate the estimated value of burnt $\mathrm{Ha}(\mathrm{Y})$ as a function of all the explanatory variables included in the model $\left(\mathrm{X}_{\mathrm{i}}\right)$ it is necessary to unmake the logarithm transformation that was done in the beginning of the analysis:

$$
\begin{gathered}
\log _{10}(\mathrm{Y})=\mathrm{b}_{0}+\Sigma \mathrm{b}_{\mathrm{i}} \mathrm{X}_{\mathrm{i}} \\
\mathrm{Y}=10^{\mathrm{b} 0+\Sigma \mathrm{bi} \mathrm{Xi}} \\
\mathrm{Y}=10^{\mathrm{b} 0}\left(10^{\mathrm{b} 1}\right)^{\mathrm{X} 1}\left(10^{\mathrm{b} 2}\right)^{\mathrm{X} 2}\left(10^{\mathrm{b} 3}\right)^{\mathrm{X} 3} \ldots\left(10^{\mathrm{b} 15}\right)^{\mathrm{X} 15}
\end{gathered}
$$

or:

$$
\mathrm{Y}=10^{\mathrm{b} 0} \Pi\left(10^{\mathrm{bi}}\right)^{\mathrm{Xi}}
$$

Using this final expression that relates the number of Ha. burnt with the set of predictors, the results in Table 3, Model 3 can be interpreted as:

- In those instances that the fire is detected by a permanent guard, there is a reduction of $14,5 \%$ in the total number of burnt Ha., all other factors remaining constant.

- A fire that happens in a location that is considered to have a $10 \%$ risk of ignition, will have a size $6.7 \%$ smaller that a fire that happens in a location that is considered not to be at any risk

Since the effects of the explanatory variables in reducing of the size of the fire are not constant for all the range of values that they can take, it is easier to visualize them through the 
use of graphics. Figures 1, 2, 3, 4 show the percent reduction in the number of burnt Ha that is achieved with each of the four factors that the model predicted to have a negative effect in the size of the fire. The detection by a permanent guard is not considered because it is not a continuous variable. Figure 3, for example, shows the evolution of the effectiveness of helicopters as a function of their number. From 0 to 1, the number of burnt $\mathrm{Ha}$ is reduced a $10 \%$. However, from 7 to 8 , the marginal reduction in the number of burnt $\mathrm{Ha}$. is $5 \%$, having therefore a decreasing rate of performance.

This finding is relevant since it means that when the fire has started, a quick response is very important since the first units are the ones that may have a major effect on the control of the fire and on its final size. 


\section{Figure 1}

Percent reduction in the number of burnt $\mathrm{Ha}$.

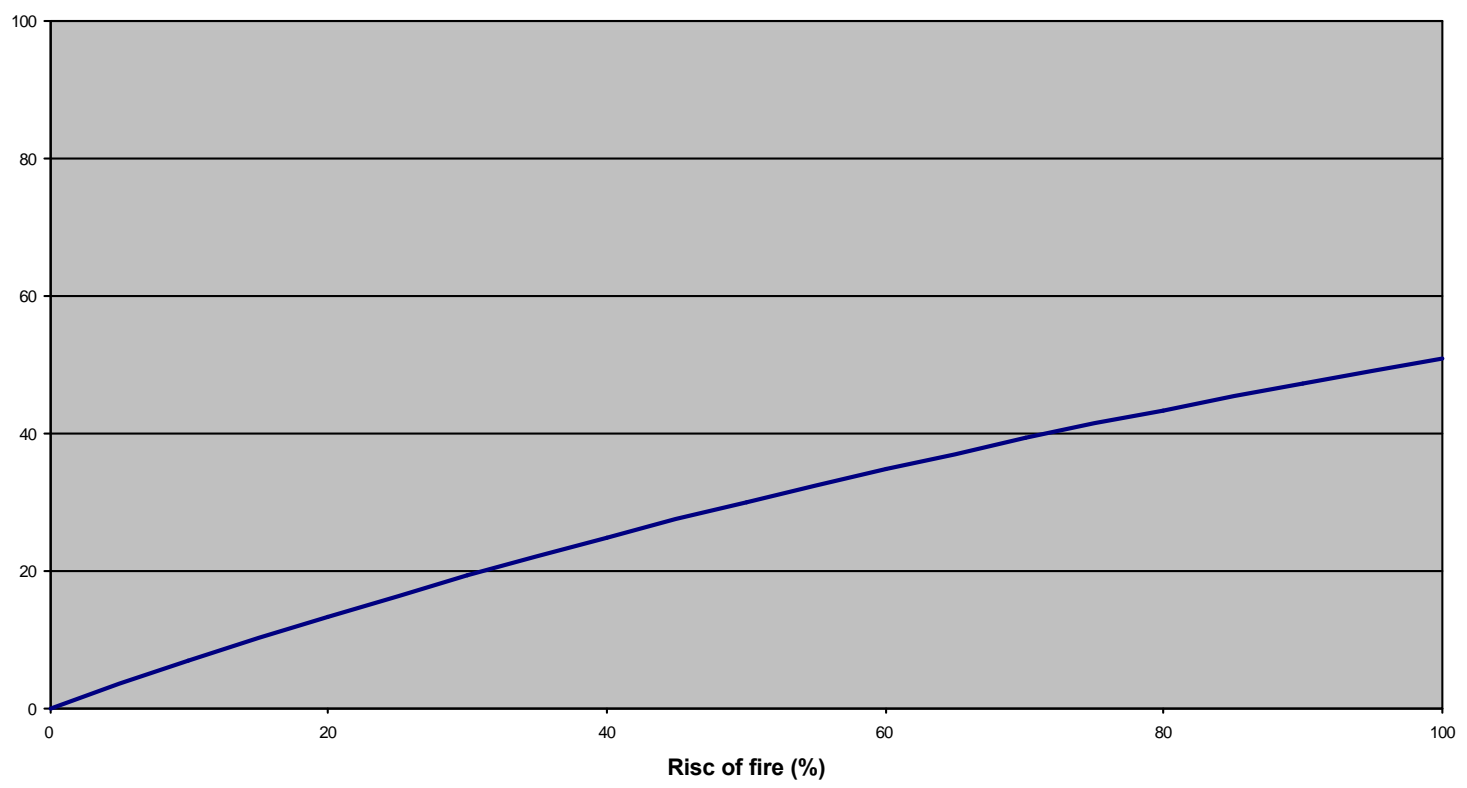

Figure 2

Percent reduction in the number of burnt $\mathrm{Ha}$.

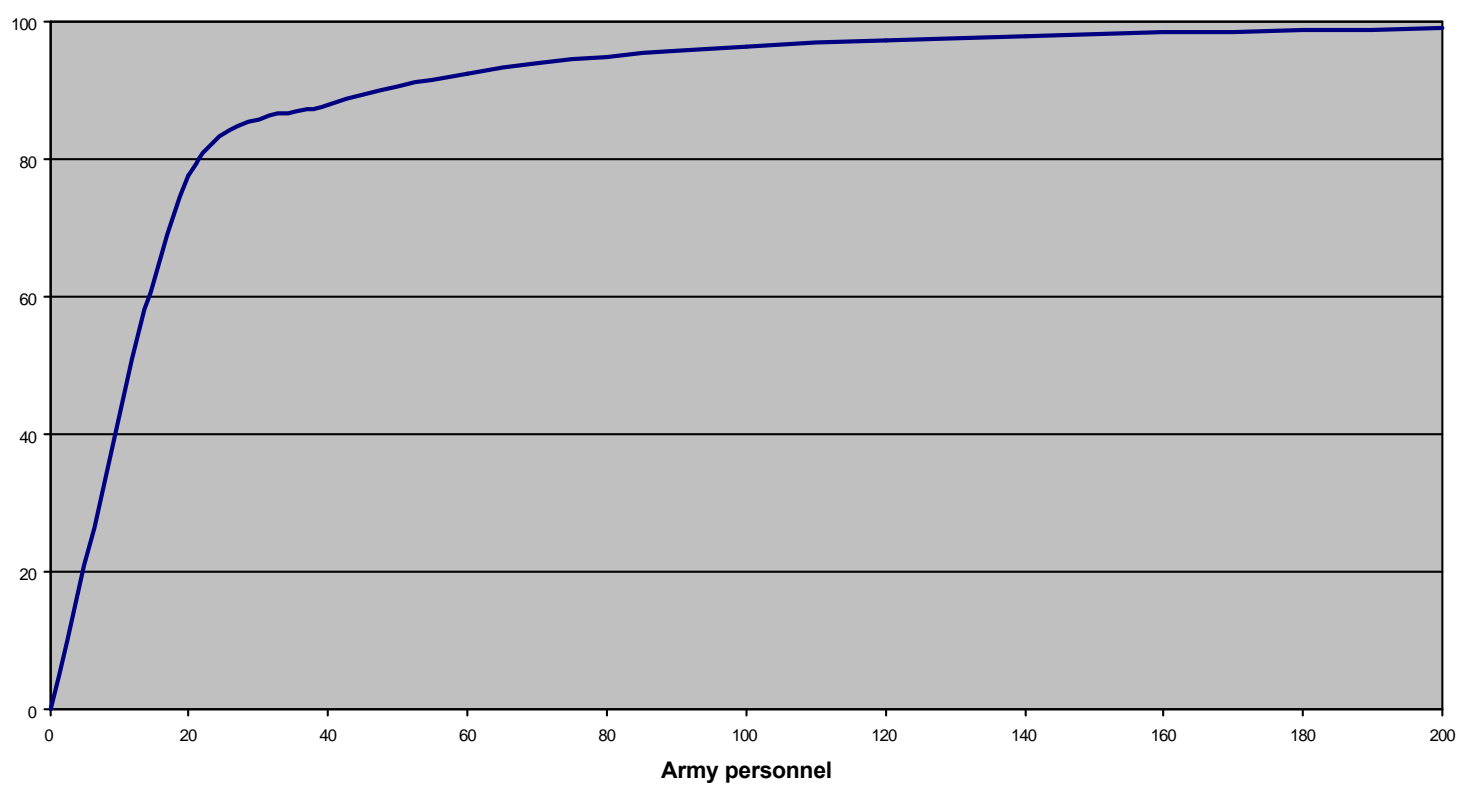


Figure 3

Percent reduction in the number of burnt $\mathrm{Ha}$.

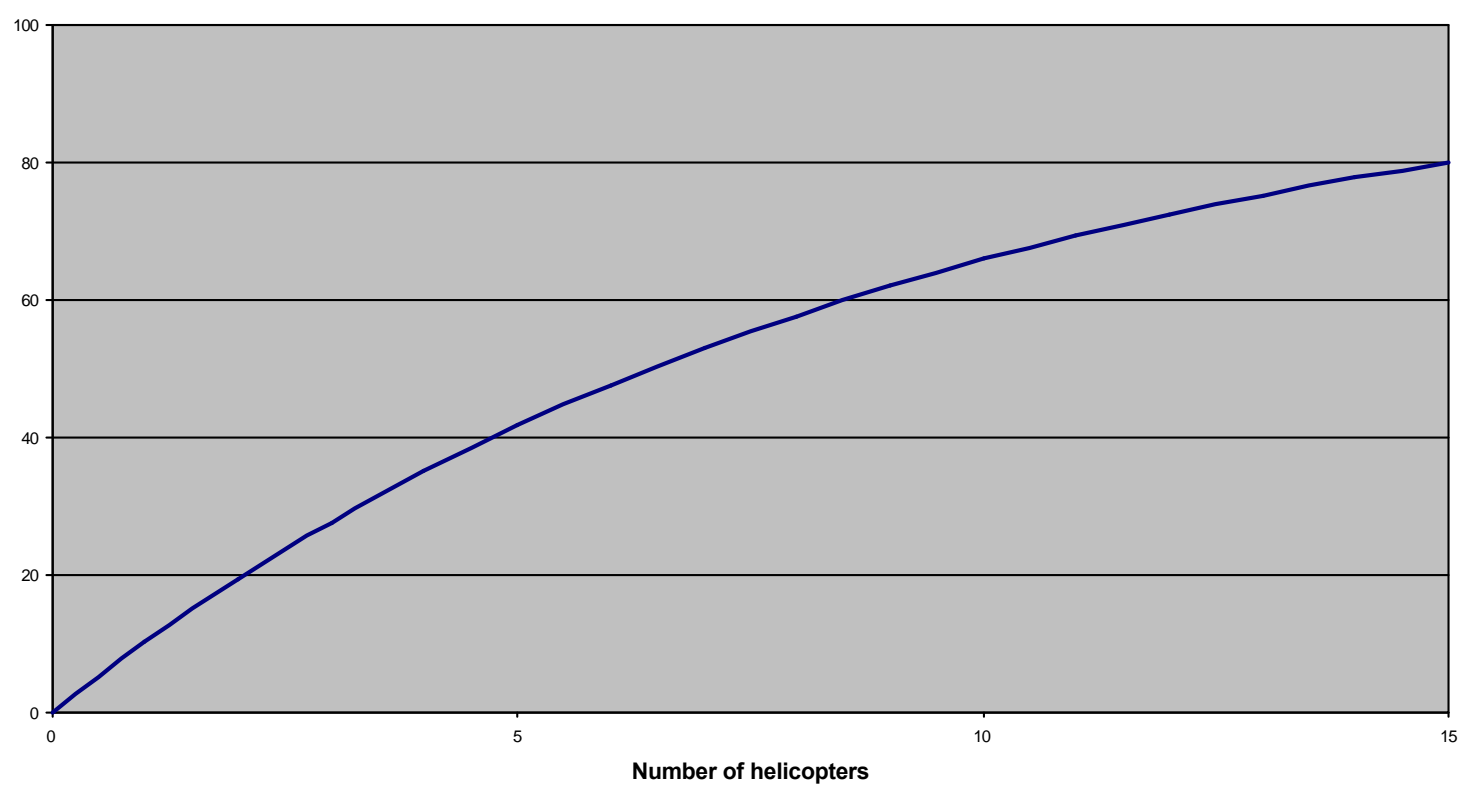

Figure 4

Percent reduction in the number of burnt $\mathrm{Ha}$.

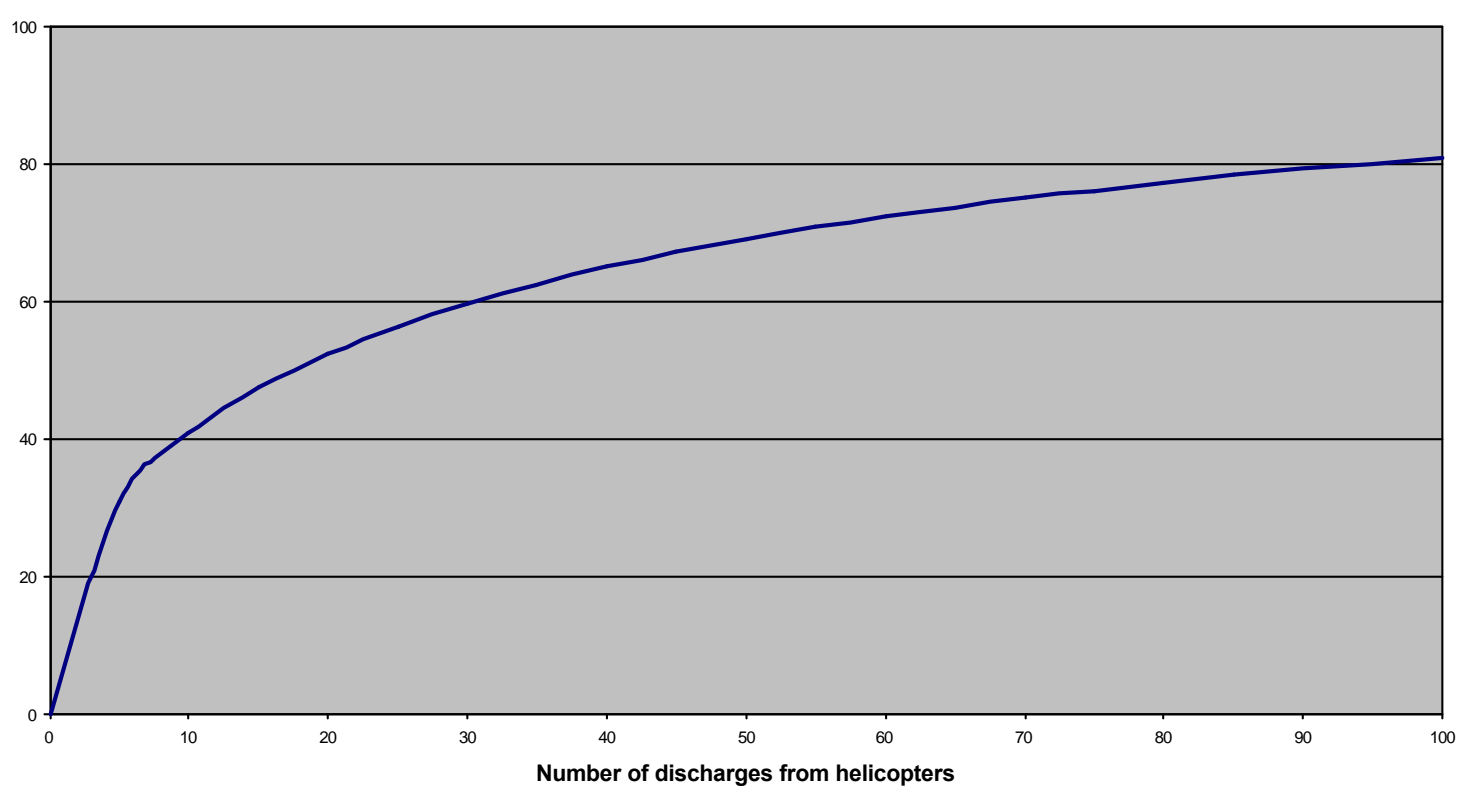




\section{References}

- Andrews, P.L.(1986). BEHAVE: Fire Behavior prediction and fuel modeling system. Burn subsystem, part 1. USDA: Forest Service.

- Burgan, R.E.; Rothermel, R.C. (1986). BEHAVE: Fire Behavior prediction and fuel modeling system. Fuel subsystem, GTRI-167 . USDA: Forest Service.

- Dansereau, P.R.; Bergeron, Y. al. (1993) "Fire history in the southern boreal forest of northwestern Quebec", Canadian Journal of Forest Research. Vol. 23, p. 25-32.

- Davis, K.P. (1959). Forest Fire, control and use. New York, McGraw Hill.

- Deeming J.E. et al. (1978). The National Fire-Fire Danger Rating System. USDA Forest Service GTRI-39

- Hamilton, L. C. (1992). Regression with Graphics. A Second Course in Applied.

Statistics. Belmont: Brooks/Cole Publishing Company.

- Hartwig, F. \& Dearing, B. E. (1990) Exploratory Data Analysis. Newbury Park: Sage

Quantitative Applications in the Social Sciences, 16.

- ICONA (1982). Manual de Predicción del peligro de incendios forestales. Madrid: ICONA, Ministerio de Agricultura, Pesca y Alimentación.

- Kurien, M.; Bakhshish, S. (1996). "Role of Community Institutions in Fire Control in Haryana”, Haryana Forest Department and Tata Energy Research Institute, New Delhi, India. Joint Forest Management Series, no.23.

- Johnson, E.A.; Van Wagner, C.E. (1985). “The theory and use of two fire history models”, Canadian Journal of Forest Research. Vol. 15, p. 214-220.

- Lozier, J. (1976). "Volunteer Fire Departments and Community Mobilization", Human Organization, Vol. 35, p. 345-354.

- Martell, D.L.; Bevilacqua, E. (1989). "Modelling seasonal variation in daily people-caused forest fire ocurrence", Canadian Journal of Forest Research. Vol. 19, p. 1555-1563.

- Palmieri, S.; Cozzi, R. (1983). "Il ruollo della metereologia nella prevenzioni e controllo degli incendi boschivi”, Rivista di Meteorologia Aeronautica, XLIII, 4.

- Pyne, S.J.(1984). Introduction to wildland fire. Fire management in the United States. New York: John Wiley and Sons.

- Rothermel, R.C. (1972). A mathematical model for predicting fire spread in wildland fuels. GTRI-11. USDA Forest Service

- Tukey, J. W. (1977). Exploratory Data Analysis. Reading: Addison Wesley. 